\title{
Risk management: FIFA's approach for protecting the health of football players
}

\author{
Colin W Fuller, Astrid Junge, Jiri Dvorak
}

FIFA Medical Assessment and Research Centre, Zurich, Switzerland

\section{Correspondence to}

Colin Fuller, FIFA Medical Assessment and Research Centre, FIFA-Strasse 20,

PO Box 8044 Zurich,

Switzerland:

colin.fuller@f-marc.com

Received 29 September 2011 Accepted 30 October 2011

Published Online First

5 December 2011

\begin{abstract}
Background Sport and exercise have long-term health benefits, but there is also a risk that participants will sustain injuries and/or ill health from these activities. For this reason, international sports governing bodies have a responsibility to identify the risks that exist within their sport and to provide guidance to participants and other stakeholders on how these risks can be controlled within acceptable levels.
\end{abstract}

Purpose To demonstrate how Fédération Internationale de Football Association (FIFA), as football's governing body, uses a risk management framework to identify, quantify, mitigate and communicate the risks of injury and ill health in football for men, women and children in all environments.

Method All the research papers published by FIFA's Medical Assessment and Research Centre (F-MARC) during the period 1994 to 2011 were reviewed and categorised according to an established sport-related risk management framework.

Conclusions F-MARC investigated and mitigated 17 areas of risk to footballers' health in a coherent and consistent approach through the process of risk management.

\section{INTRODUCTION}

Corporate governance became an important business issue in the early 1980s; initially, attention focused on protecting company interests, but then moved to shareholders' financial interests. ${ }^{1}$ In the $1990 \mathrm{~s}$, a number of committees reviewed and reported on various aspects of corporate governance: ${ }^{2-4}$ the Report of the Hampel Committee ${ }^{2}$ stated 'The board should maintain a sound system of internal control to safeguard shareholders' investment and company's assets. This covers financial controls and operational and compliance controls, as well as risk management, since there are potential threats to shareholders' investments in each of these areas'(p21). The Report of the Turnbull Committee, ${ }^{4}$ which provided guidance on how to implement an 'internal control' system to meet the requirements of corporate governance, stated: 'the guidance is based on the adoption by a company's board of a riskbased approach to establishing a sound system of internal control and reviewing its effectiveness' (p4) and, in particular, 'the purpose of internal control is to help manage and control risk appropriately rather than to eliminate it'(p5).

Generally, sport and exercise are considered to have long-term health benefits for participants; however, all physical activity carries risks that participants will sustain an injury or ill-health and these must be balanced against the benefits. ${ }^{56}$
Each sport has a different level of risk associated with it, which is related to the underlying characteristics of the sport, the laws or the rules that govern how the sport is played and, in the case of team sports, the respect participants have for their fellow participants. As for the boards of directors in any business, international sports governing bodies have a responsibility to demonstrate that corporate governance principles have been implemented within their operations, including the identification and characterisation of the risks that exist within their sport, and to provide guidance to participants and other stakeholders on how the risks can be controlled within acceptable levels. Individuals can then make informed choices about which sports align with their own risk-taking behaviour. ${ }^{6}$

Football is the most popular team sport worldwide for men, women and children; $;^{7}$ therefore, it is particularly important that the risks associated with this sport are managed effectively. Fédération Internationale de Football Association (FIFA), as the international governing body, recognised this responsibility and created FIFA's Medical Assessment and Research Centre (F-MARC) in 1994 specifically to investigate risks to players' health that were associated with football. The process of risk management provides a comprehensive framework within which to study the risks of injury and ill health because it includes issues related to risk identification, estimation, perception, evaluation, mitigation and communication. ${ }^{8}$ The objective of this paper is to summarise how the risk management approach has been used by F-MARC to provide a coherent and transparent approach for protecting the health of players with the aim of encouraging other sports governing bodies to adopt a similar approach.

\section{The risk management framework}

Risk management provides a formal framework within which organisations can identify, classify and investigate risks using a logical and transparent protocol. It is essential to appreciate that the objective of the risk management process is not to reduce risks to zero, but to control them within acceptable levels and then to ensure that stakeholders are made aware of the residual risks. The framework adopted by F-MARC has been described previously ${ }^{89}$ and those publications should be referred to for a detailed discussion of the individual elements of the framework. However, for the benefit of the discussion in this paper, a version of the framework (figure 1) and the core definitions are presented here. Risk is a 


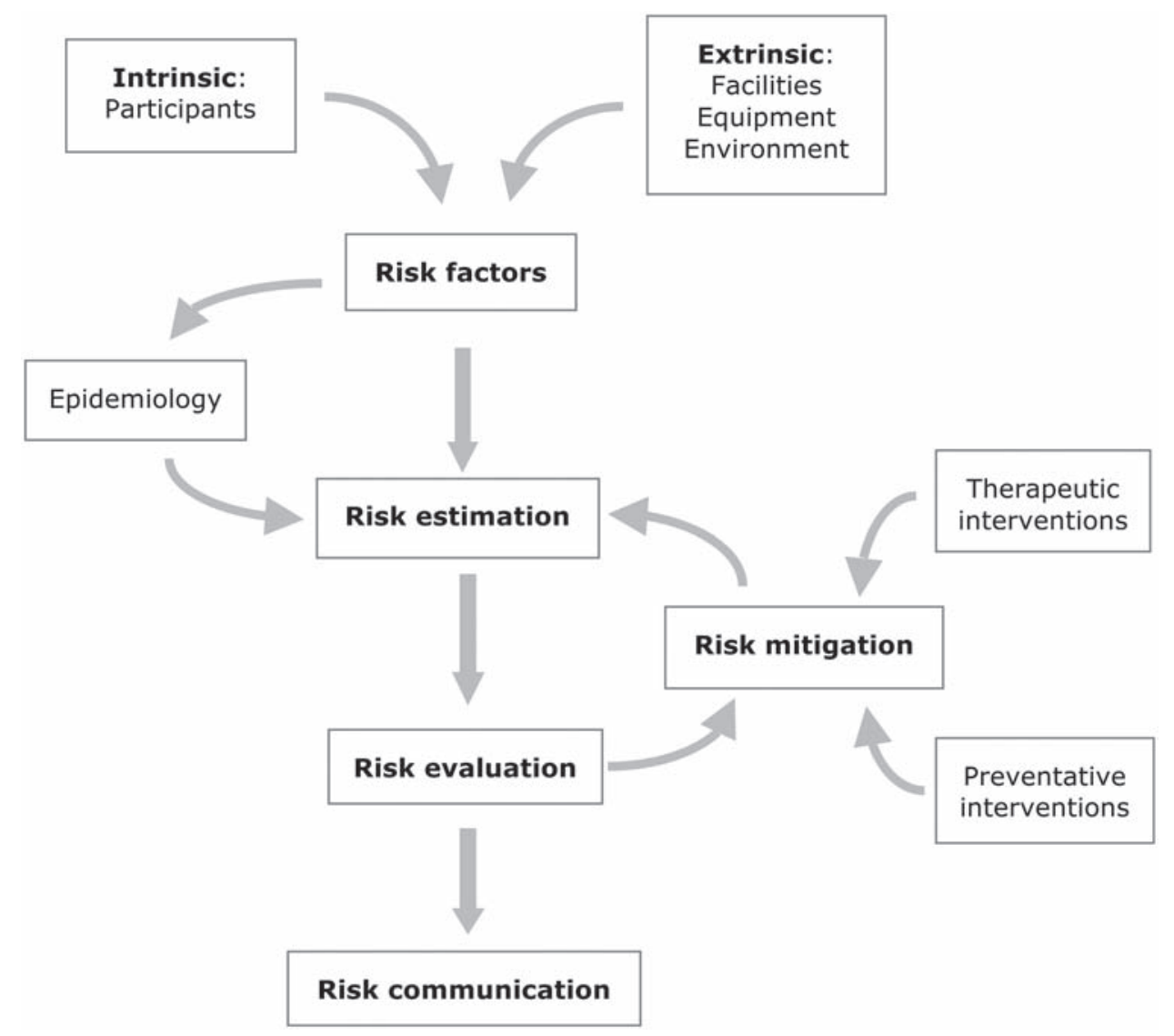

Figure 1 Injury risk management model (adapted from Fuller). ${ }^{8}$

combined measure of the probability of occurrence and the consequences of an adverse event; a risk factor is a condition or a situation that predisposes an individual, organisation or society to an adverse event; risk estimation is a quantitative or a qualitative measurement of the risk associated with specified risk factors; risk evaluation is the comparison of measured or perceived risks against an organisational, national and/or international standard of an acceptable level of risk; risk mitigation is the introduction of measures to reduce the level of individual, organisational or societal risk arising from specified risk factors. The central part of the management framework is the identification of intrinsic and extrinsic risk factors affecting participants followed by the estimation and evaluation of the level of risk associated with these factors in a process collectively known as 'risk assessment'. If the level of risk associated with any of the individual risk factors is considered to be too high, then potential mitigation strategies should be considered, including the potential for reducing either the incidence and/or the nature and severity of injuries and ill health. Epidemiological studies using appropriate cohort populations or randomised control trials are employed to provide an evidence base for estimating the levels of risk before and after the introduction of risk mitigation initiatives. Finally, the residual levels of the risk associated with individual risk factors should be communicated to stakeholders in an appropriate and accessible format to encourage informed critical discussions about the risks of injury and ill health at all levels of play and in all settings.

There is a recognised process within FIFA for managing potential injury and health risks in football: issues can be raised by a variety of stakeholders, including players, match officials, FIFA Committees, FIFA confederations and member associations, external bodies and from within F-MARC. Potential risks are evaluated by F-MARC using the existing published information; a decision is then made as to whether more detailed evaluations of the scientific literature or novel research studies are required. The outcomes and recommendations from these deliberations and research studies are formally presented by F-MARC to FIFA's Medical Committee for onward communication to FIFA's Executive Committee, which may then make decisions on regulations or make representations for law changes to the International Football Association Board. ${ }^{10}$ The results and conclusions from every research study are submitted for publication in international, peer-reviewed scientific journals with no input or influence from any other part of the FIFA organisation. Based on the results obtained from literature reviews and research studies, F-MARC proposes and evaluates risk mitigation strategies; if successful, these proposals are then translated into guidance documents for stakeholders.

The following discussion presents a number of F-MARC research studies in order to illustrate how the risk management process brings a wide range of issues together within a single unified management framework and to demonstrate how FIFA communicates the results obtained in the studies to the scientific community and to the wider football family.

\section{DISCUSSION}

The discussion presented relates to the risks of injury and ill health to football players - professional and amateur; F-MARC also investigates risk factors for match officials but these are not included in this review. 
Table 1 Risk assessments: evaluations undertaken by FIFA's Medical Assessment and Research Centre

\begin{tabular}{llll}
\hline Risk factor & Literature review (L)/research (R) study $\quad$ Action required
\end{tabular}

Participant related Age

Comparison of the incidence of injury for male amateur players as a function of age $(R)^{23}$

Assess whether over-age players take part in agerestricted competitions $(\mathrm{R})^{24}$

Drugs/medication Excretion of nandrolone metabolites by amateur and professional players following exercise $(\mathrm{R})^{25}$ Steroid profiles in elite footballers $(R)^{26}$

Evaluate the use of medication during competition $(\mathrm{R})^{27}$

Gender

Comparison of incidence and severity of injury for international male and female players $(R)^{28}$

Comparison of incidence and severity of injury for amateur male and female players $(\mathrm{R})^{29}$

Medical history Risk factor analysis $(\mathrm{R})^{30}$

Precompetition musculoskeletal evaluation $(\mathrm{R})^{31}$

Precompetition cardiovascular assessment $(R)^{32}$

Psycho-social Impact of player behaviour on fair play $(R)^{33}$ Impact of psychological characteristics on fair play $(\mathrm{R})^{34}$

Standard of play Comparison of the incidence of injury at international men's tournaments $(\mathrm{R})^{28}$

Comparison of the incidence of injury at international women's tournaments $(\mathrm{R})^{28}$

Tackling

Comparison of risks associated with making different types of tackle by male players $(\mathrm{R})^{35}$

Comparison of risks associated with making different types of tackle by female players $(R)^{36}$

Extrinsic factors

Facility-related

Playing surface

Comparison of the incidence of injury among nonprofessional players on artificial turf and grass playing surfaces $(R)^{29}$

Comparison of the incidence of injury among professional players on artificial turf and grass playing surfaces $(\mathrm{R})^{37}$

Stadium design Assess the environs of the playing area that may impact on a player's safety $(\mathrm{R})^{38}$

Equipment-related

Headgear/footballs Biomechanical analysis of protection offered by headgear $(\mathrm{R})^{39}$

Biomechanical analysis of football properties $(R)^{40}$

Environment-related

Altitude

Effect of altitude on football performance $(L)^{41}$

Preparations for playing football at altitude $(\mathrm{L})^{42}$

Being tackled

Comparison of risks associated with different types of tackle on male players $(\mathrm{R})^{35}$

Comparison of risks associated with different types of tackle on female players $(\mathrm{R})^{36}$

Playing position Impact of playing position on the incidence of injury among male players $(\mathrm{R})^{35}$

Impact of playing position on the incidence of injury among female players $(\mathrm{R})^{43}$

Ramadan

Impact of Ramadan on physical and football performance $(\mathrm{R})^{44}$

Influence of Ramadan on physiological parameters $(\mathrm{R})^{45}$

Refereeing

Assess referees' decision-making in player injury situations $(\mathrm{R})^{46}$

Stage in match

Effect of stage in match on the incidence of injury in men's football $(\mathrm{R})^{47}$

Effect of stage in match on the incidence of injury in women's football $(R)^{36}$

Temperature Playing football in hot environments $(L)^{48}$

Effect of heat on the physical activity of footballers $(\mathrm{R})^{49}$
Incidence of injury increases with age and is highest among senior players

Some evidence of overage players taking part in agerestricted competitions

Variations in postactivity urine levels of some steroids in non-drug-taking players occur across ethnic groups; results indicate that individual steroid profiling should be considered. High usage of NSAIDs by players

Incidence of injury is higher among male players than among female players but female players are significantly more likely to sustain ACL injuries than men

Previous injury most important risk factor for injury. Players frequently returned to play while still feeling the effects of an injury. Players may have undiagnosed cardiovascular problems when playing high-level football A wide range of psychosocial factors impacted on players attitudes towards fair play

For men, the incidence of injury at World Cups lower than the incidences of injury at $<17$ and $<20$ tournaments; for women, no clear trends

Video analysis of tackles showed that players making a tackle were more likely to be injured when tackles involved a clash of heads or were two-footed

There were no significant differences in the overall incidence of injury for male and female footballers playing on artificial turf compared with natural grass

Hazardous situations and objects were found in the environs of the playing area

No evidence found that commercially available headgear provided a significant level of head protection to players Some evidence that reducing ball size and ball pressure could reduce impact forces during heading

Players from low altitude must acclimatise for 1-2 weeks before competing at high altitude to avoid adverse effects on performance

Video analysis of tackles showed that players being tackled were more likely to be injured when the tackles involved a clash of heads or were two-footed

No significant difference found in the incidence of injury as a function of playing position for men but forwards and defenders showed higher incidences of injury among female players

Changes in sleep and nutrition patterns during Ramadan had no significant effects on physical performance

Current laws were adequate to protect players from injury but in matches referees were under pressure to make difficult decisions in high pressure situations and match referees often failed to punish players in incidents leading to injury

For men, there were significantly more injuries in the second half of matches than in the first half but for women there were no differences. Effects in the men's game may be caused by fatigue

High temperatures, especially when accompanied by Develop a statement on playing football high humidity, have an adverse effect on performance in hot conditions
Develop techniques to determine the age of young players and monitor the age of players competing in age-restricted competitions

Instigate drug-testing procedures in football to support WADA. Information to team physicians on the side effects of NSAIDs

Develop a prevention programme to reduce the incidence of $A C L$ injuries among female players

Review the best practice procedures and develop protocols to evaluate player's medical condition prior to FIFA tournaments

Review FIFA policy towards all aspects of 'fair play'

Develop an injury prevention programme for players of all skill levels.

Review the laws of the game

Maintain quality criteria for FIFA-approved artificial turf pitches

Produce stadium design guidelines

Review technical specifications for water uptake of balls

Develop a statement on playing football at altitude

Review the laws of the game and the punishments given against players causing severe injuries

None required

Provide advice on nutrition; recommendation that players ensure adequate sleep and nutrition during Ramadan

Review referees training programmes

Develop an injury prevention programme for players of all skill levels

A, World Anti-doping Agency. 
Table 2 Risk mitigation: strategies developed by FIFA

\begin{tabular}{|c|c|}
\hline Risk factor & Prevention $(\mathrm{P})$ and therapeutic $(\mathrm{T})$ risk mitigation action \\
\hline \multicolumn{2}{|l|}{ Intrinsic factors } \\
\hline \multicolumn{2}{|l|}{ Participant-related } \\
\hline Age determination & Developed MRI examination technique for assessing the age of players taking part in FIFA U-17 tournaments $(\mathrm{P})^{50}$ \\
\hline \multirow[t]{3}{*}{ Drugs/medication } & Prepared a guidance document on doping in football $(\mathrm{P})^{51}$ \\
\hline & Defined drug-testing procedures and publication of doping results in football $(P)^{52}$ \\
\hline & Established a network of F-MARC Doping Control Officers and doping control workshops for physicians $(\mathrm{P})^{52}$ \\
\hline Concussion & Prepared consensus statements on diagnosis, treatment and return-to-play criteria for concussion in sport $(\mathrm{T})^{53-55}$ \\
\hline Functional rehabilitation & Proposed technique for quantifying functional rehabilitation from injury $(T)^{56}$ \\
\hline Gender & Prepared a guidance document on health and fitness for female players $(\mathrm{P})^{57}$ \\
\hline \multirow[t]{2}{*}{ Medical history } & Developed and implemented a precompetition medical assessment protocol for professional players $(\mathrm{P})^{58}$ \\
\hline & Reviewed the best practice procedures for the management of on-field sudden cardiac arrest $(\mathrm{T})^{59}$ \\
\hline \multirow[t]{3}{*}{ Physical condition } & Developed, implemented and evaluated an injury prevention educational programme for youth players $(P)^{60}$ \\
\hline & Developed, implemented and evaluated the ' $11+$ ' injury prevention programme for players $(\mathrm{P})^{61}$ \\
\hline & Developed, implemented and evaluated an ACL injury prevention programme for female players $(\mathrm{P})^{62}$ \\
\hline Psycho-social & Continued promotion of the FIFA 'fair play' campaign to encourage all aspects of fair play and respect for others $(\mathrm{P})^{63}$ \\
\hline \multirow[t]{2}{*}{ Tackling } & Recommended to IFAB that tackling from behind should be a red card offence in 1998 (P) \\
\hline & Recommended to IFAB that the use of the elbow to the head when tackling should be a red card offence in 2006 (P) \\
\hline
\end{tabular}

Extrinsic factors

Facility-related

Medical facilities

Playing surface

Established FIFA Medical Centres of Excellence to provide expert medical support for players in 2005 (T)

Developed the 'FIFA Quality Concept for Football Turf' to ensure that the risk of injury on artificial turf pitches is no greater than on natural grass surfaces $(\mathrm{P})^{64}$

Stadium design

Developed design criteria for football stadiums that took into account player safety $(\mathrm{P})^{65}$

Specified safe design of goalposts in the Laws of the Game $(P)^{66}$

Equipment-related

Footballs

Developed the 'FIFA International Matchball Standard' to ensure that footballs reach and maintain standards for parameters such as weight, water absorption and pressure $(\mathrm{P})^{67}$

Environment-related Altitude

Prepared a consensus statement on playing football at altitude $(P)^{68}$

Being tackled

Recommended to IFAB that tackling from behind should be a red card offence in 1998 (P)

Recommended to IFAB that the use of the elbow to the head when tackling should be a red card offence in 2006 (P)

Ramadan/nutrition

Prepared a guidance document on nutrition for footballers $(P)^{69}$

Temperature

Prepared a position statement on playing football in hot environments $(P)^{70}$

ACL, anterior cruciate ligament; FIFA, Fédération Internationale de Football Association; F-MARC, FIFA's Medical Assessment and Research Centre; IFAB International Football Association Board.

\section{Risk assessment}

Van Mechelen et al discussed the management of sports injuries in terms of internal (intrinsic) and external (extrinsic) risk factors and presented a research model for addressing this issue, ${ }^{11}$ while Meeuwisse et al discussed the causative role of intrinsic and extrinsic risk factors in sports injuries and summarised this in an injury causation model. ${ }^{12}$ The initial focus for any sportrelated risk management system reflects these models through the identification of the intrinsic and extrinsic risk factors closely followed by an estimation and evaluation of the level of risks in the combined process referred to as risk assessment. If the results of these risk assessments are to be universally accepted in a worldwide sport such as football, it is essential that the risk estimations be based on robust and consistent definitions and procedures. To ensure unequivocal acceptance of its research results, F-MARC initiated an international consensus meeting to produce an agreement on the procedural criteria that should be used for epidemiological studies in football: the agreement addressed the definitions of injury, severity and exposure, classification categories for the location and type of injury and reporting parameters. The conclusions and recommendations from this consensus meeting, which were published simultaneously in three international sports medicine journals, ${ }^{13}$ have become the benchmark for epidemiological studies in football and have also provided the basis for the development of similar consensus agreements in other sports. ${ }^{14-16}$
The overall strategy adopted by F-MARC has been to monitor all FIFA tournaments since 1998 in order to provide baseline data on the level of risk and to identify the step changes and trends in the incidence, nature and causes of injuries. This ongoing surveillance programme is supplemented with the studies of specific risk factors, which can be subcategorised conveniently into intrinsic (participant-related) and extrinsic (facility-, equipment- and environment-related) factors. Studies of risk factors undertaken by F-MARC during the period 1994-2010 together with the key outcomes and the recommended actions are summarised in table 1; of these studies, 15 addressed intrinsic risk factors and 18 extrinsic factors (facilities: 3; equipment: 2; environment: 13).

\section{Risk mitigation}

Although investigating and evaluating risk factors in football is important, an essential aspect of the risk management process is translating the results and recommendations from risk assessments into effective risk mitigation proposals. There are two general ways in which the risk of injury/ill health from a particular risk factor can be mitigated: ${ }^{5}$ either through risk acceptance (eg, insurance, self/organisational acceptance) or through risk reduction (eg, control, elimination). Risk control can be achieved through reductions in the incidence with which adverse events occur (preventive interventions) or through reductions in the severity of the outcomes 
Table 3 Risk communication: strategies developed by F-MARC

\begin{tabular}{ll}
\hline Communication format & Information provided ${ }^{10}$ \\
\hline Conferences & FIFA International Football Medicine Conferences (4) in 2001 (Los Angeles); 2006 (Dusseldorf); 2009 (Zurich); 2010 (Sun City) \\
Journal supplements & F-MARC-sponsored Journal Supplements (11) containing 136 peer-reviewed research papers \\
Laymen publications & Laymen publications (4) about nutrition, doping, female players and F-MARC research projects \\
Manuals & F-MARC Manuals (3) covering Football Medicine, ${ }^{71}$ Emergency Medicine $^{72}$ and F-MARC Research ${ }^{73}$ (also available in CD format and \\
Medical Centres of Excellence & on FIFA web pages) \\
Peer-reviewed research publications & Medical Centres of Excellence (24) based in 17 countries situated on six continents \\
Posters & Peer-reviewed research papers (79), excluding papers published in F-MARC journal supplements \\
Training courses & FIFA Futuro III medical education training courses for sports physicians and physiotherapists presented on six continents \\
Videos & F-MARC 11+ injury prevention programme; ambassador players promoting '11 for Health' programme \\
Websites & Medical Education and players' health on FIFA websites and extranet \\
\hline
\end{tabular}

CD, compact disc; FIFA, Fédération Internationale de Football Association; F-MARC, FIFA's Medical Assessment and Research Centre.

from the adverse events (therapeutic interventions). In terms of preventive interventions, reductions in incidence can be achieved through measures directed at physical (eg, equipment), management (eg, laws of the game) or human (eg, player behaviour) aspects of the game. In terms of therapeutic interventions, reductions in severity can be achieved through improvements in injury/ill-health treatment (eg, provision of specialist medical expertise and facilities) or rehabilitation (eg, improvements in functional recovery procedures). These approaches can be summarised within the two-dimensional Haddon matrix of injury prevention; dimension 1: time of risk - pre-event, event, postevent; dimension 2: control strategy-physical, management, human. ${ }^{9}$ All these combinations have been used by FIFA and proposals for these initiatives have taken a variety of formats, including technical specifications, such as those for artificial turf, footballs and stadiums; implementation protocols, such as the 11+ injury prevention programme and doping control procedures; consensus statements, such as those for concussion, altitude and heat; and general guidance documents, such as those for nutritionand gender-related issues (table 2). F-MARC's philosophy is to ensure that all recommendations for risk mitigation are evidence based and in this respect strategies proposed are always underpinned by the peer-reviewed research results or the best practice procedures that have been identified from literature reviews.

\section{Risk communication}

Risk communication is perhaps the most important element of the risk management process because without an effective communication strategy, risk mitigation strategies will not be accessible to stakeholders. To provide an effective communication strategy, it is important to present information in a number of appropriate formats: this presents a challenge because potential stakeholders include, for example, researchers, physicians, physiotherapists, sports scientists, players, coaches, parents, referees, member associations, teachers and administrators. To reach such a diverse range of people, F-MARC employs an equally diverse range of communication formats, such as peer-reviewed research papers, journal supplements, lectures, FIFA medical conferences, training courses, centres of excellence, books, videos, laymen publications and web pages. Because of the large number of F-MARC communication activities, it is not possible to reference each individual item in this document; however, the information contained within table 3 and many other examples can be accessed through F-MARC's Medical Network website, ${ }^{17}$ which is freely available.

\section{CONCLUSIONS}

Although the risks of injury and ill health are generally higher in contact sports than in non-contact sports, many athletes choose to take part in contact rather than in non-contact sports. The risks in contact sports could be reduced significantly simply by making major changes to the laws of the sport; this, however, would undoubtedly change the fundamental nature of the sport and that would make the sport unacceptable to many of the athletes taking part. These athletes would almost certainly leave the sport and seek out other sports that more closely match their needs and aspirations. Each of the international sports governing bodies therefore has a responsibility to eliminate, wherever possible, unacceptable risks of serious injury and even death and to reduce the level of other risks so far as is reasonably practicable, while not fundamentally changing the nature of their sport. F-MARC has followed this philosophy within football since 1994 using the risk management approach and the examples of risk assessment, risk mitigation and risk communication presented here demonstrate how this process can be implemented effectively; for example, the implementation of an injury prevention programme in football reduced the incidence of injury and reduced national healthcare costs. ${ }^{18}$ By adopting this approach, F-MARC working alone, in conjunction with other researchers or with other governing bodies, has been at the forefront of many sports medicine initiatives over the past 17 years. Of particular note are activities associated with injury epidemiology, injury prevention, precompetition medical assessment, sudden cardiac death, playing at altitude and in heat, management of concussion, artificial turf surfaces, drug testing and age determination. In addition, F-MARC has developed new ways in which governing bodies communicate risks and risk mitigation information to stakeholders, including the use of journal supplements, guidance documents, videos and dedicated web pages. Finally, new initiatives aimed at providing better medical services within football have been established in the form of FIFA Medical Centres of Excellence and the freely available web-based FIFA medical network for sports physicians and physiotherapists.

Other bodies around the world also actively promote the use of risk management in sport. In the UK, UK Sport ${ }^{19}$ published a guidance document for managing the risks associated with sports events; in Ireland, the International Rugby Board ${ }^{20}$ reviewed the risks of catastrophic injury in the sport and subsequently established a worldwide injury surveillance study to collect more detailed information about the risks; Standards Australia published guidelines for risk management in sport and recreation; ${ }^{21}$ and in Canada, the 2010 


\section{What this study adds}

- Provides a framework within which international sports governing bodies can demonstrate governance with respect to managing injury risk factors associated with a sport.

- Demonstrates how FIFA has managed the risks of injury associated with football.

- Demonstrates how FIFA has managed the risks of ill health associated with football.

Legacies Now organisation produced a risk management guide for community sports organisations. ${ }^{22}$ It is hoped that further sports bodies will recognise the importance of understanding and managing risks to athletes and adopt similar proactive risk management approaches.

Contributors CF: developed the risk management framework; contributed to the structure of this paper; prepared the first draft; edited and approved the final text. AJ: contributed to the structure of this paper; reviewed the first draft; edited and approved the final text. JD: contributed to the structure of this paper; reviewed the first draft; edited and approved the final text.

Competing interests None.

Provenance and peer review Not commissioned; externally peer reviewed.

\section{REFERENCES}

1. Smith T. Accounting for Growth: Stripping the Camouflage from Company Accounts. London: Century Business 1992.

2. Hampel R. Report of the Committee on Corporate Governance. London: Gee Publishing 1998.

3. Cadbury A. Report of the Committee on the Financial Aspects of Corporate Governance. London: Gee Publishing 1992.

4. Internal Control Working Party of the Institute of Chartered Accountants in England \& Wales. Internal Control: Guidance for Directors on the Combined Code. London: The Institute of Chartered Accountants in England \& Wales 1999.

5. Fuller CW, Vassie LH. Health and Safety Management: Principles and Best Practice. Harlow: FT Prentice Hall 2004.

6. Fuller CW, Ward CJ. An empirical approach for defining acceptable levels of risk: a case study in team sports. Inj Prev 2008;14:256-61.

7. Kunz M. Big count: 265 million playing football. FIFA Magazine 2007:10-15.

8. Fuller CW. Managing the risk of injury in sport. Clin J Sport Med 2007:17:182-7.

9. Fuller C, Drawer S. The application of risk management in sport. Sports Med 2004;34:349-56.

10. FIFA. The International Football Association Board. http://www.fifa.com/ classicfootball/history/law/ifab.html (accessed 23 October 2011).

11. van Mechelen W, Hlobil H, Kemper HC. Incidence, severity, aetiology and prevention of sports injuries. A review of concepts. Sports Med 1992;14:82-99.

12. Meeuwisse WH, Tyreman $\mathrm{H}$, Hagel B, et al. A dynamic model of etiology in sport injury: the recursive nature of risk and causation. Clin J Sport Med 2007:17:215-9.

13. Fuller CW, Ekstrand J, Junge A, et al. Consensus statement on injury definitions and data collection procedures in studies of football (soccer) injuries. Br J Sports Med 2006:40:193-201.

14. Fuller CW, Molloy MG, Bagate C, et al. Consensus statement on injury definitions and data collection procedures for studies of injuries in rugby union. Br J Sports Med 2007;41:328-31.

15. Pluim BM, Fuller CW, Batt ME, et al. Consensus statement on epidemiological studies of medical conditions in tennis, April 2009. Br J Sports Med 2009;43:893-7.

16. Turner M, Fuller CW, Egan D, et al. European consensus on epidemiological studies of injuries in the thoroughbred horse racing industry. Br J Sports Med 2011;Published Online First: 8 November 2011 doi:10.1136/bjsports-2011-090312.

17. FIFA. Medical Network Website. http://www.fifa.com/aboutfifa/ footballdevelopment/medical/medicalnetwork.htm (accessed 23 October 2011).

18. Dvorak J, Fuller CW, Junge A. Transferring science to life. Presented at the IOC World Conference on Prevention of Injury and IIIness in Sport, Monaco; 6-8 April 2011. http://www.ioc-preventionconference.org/OnLPMonaco.php (accessed 23 October 2011).

19. UKSport. Major Sports Events: The Guide. London: UKSport 2005.

20. Fuller CW. Catastrophic injury in rugby union: is the level of risk acceptable? Sports Med 2008;38:975-86
21. Standards Australia. Guidelines for Managing Risk in Sport and Recreation: SAA HB 246: 2002. Sydney: Standards Australia 2002.

22. 2010 Legacies Now. Risk Management Guide for Community Sport Organizations. Vancouver: 2010 Legacies Now 2011

23. Peterson L, Junge A, Chomiak J, et al. Incidence of football injuries and complaints in different age groups and skill-level groups. Am J Sports Med 2000;28:S51-7.

24. Dvorak J, George J, Junge A, et al. Age determination by magnetic resonance imaging of the wrist in adolescent male football players. Br J Sports Med 2007:41:45-52.

25. Robinson N, Taroni F, Saugy M, et al. Detection of nandrolone metabolites in urine after a football game in professional and amateur players: a Bayesian comparison. Forensic Sci Int 2001;122:130-5.

26. Strahm E, Sottas PE, Schweizer C, et al. Steroid profiles of professional soccer players: an international comparative study. Br J Sports Med 2009;43:1126-30

27. Tscholl P, Junge A, Dvorak J. The use of medication and nutritional supplements during FIFA World Cups 2002 and 2006. Br J Sports Med 2008;42:725-30.

28. Dvorak J. Osteoarthritis in football: FIFA/F-MARC approach. Br J Sports Med 2011;45:673-6.

29. Fuller CW, Dick RW, Corlette J, et al. Comparison of the incidence, nature and cause of injuries sustained on grass and new generation artificial turf by male and female football players. Part 1: match injuries. Br J Sports Med 2007;41:i20-6.

30. Dvorak J, Junge A, Chomiak J, et al. Risk factor analysis for injuries in football players. Possibilities for a prevention program. Am J Sports Med 2000;28:S69-74.

31. Junge A, Grimm K, Feddermann N, et al. Precompetition orthopedic assessment of international elite football players. Clin J Sport Med 2009;19:326-8.

32. Thünenkötter T, Schmied C, Grimm K, et al. Precompetition cardiac assessment of football players participating in the 2006 FIFA World Cup Germany. Clin J Sport Med 2009;19:322-5.

33. Fuller CW. An assessment of the relationship between behaviour and injury in the workplace: a case study in professional football. Safety Science 2005; $43: 213-24$

34. Junge A, Dvorak J, Rösch D, et al. Psychological and sport-specific characteristics of football players. Am J Sports Med 2000;28:S22-8.

35. Fuller CW, Smith GL, Junge A, et al. The influence of tackle parameters on the propensity for injury in international football. Am J Sports Med 2004;32:43S-53S

36. Tscholl P, O'Riordan D, Fuller CW, et al. Causation of injuries in female football players in top-level tournaments. Br J Sports Med 2007;41:i8-14.

37. Ekstrand J, Hägglund M, Fuller CW. Comparison of injuries sustained on artificial turf and grass by male and female elite football players. Scand J Med Sci Sports 2011;21:824-32

38. Fuller CW, Hawkins RD. Assessment of football grounds for player safety. Safety Science 1997;27:115-28.

39. Withnall C, Shewchenko N, Wonnacott M, et al. Effectiveness of headgear in football. Br J Sports Med 2005;39:i40-8; discussion i48.

40. Shewchenko N, Withnall C, Keown M, et al. Heading in football. Part 3: effect of ball properties on head response. Br J Sports Med 2005;39:i33-9.

41. Levine BD, Stray-Gundersen J, Mehta RD. Effect of altitude on football performance. Scand J Med Sci Sports 2008;18:76-84.

42. Gore CJ, McSharry PE, Hewitt AJ, et al. Preparation for football competition at moderate to high altitude. Scand J Med Sci Sports 2008;18:85-95.

43. Faude $\mathbf{0}$, Junge $A$, Kindermann W, et al. Risk factors for injuries in elite female soccer players. Br J Sports Med 2006; $\mathbf{4 0 : 7 8 5 - 9 0}$

44. Zerguini Y, Kirkendall D, Junge A, et al. Impact of Ramadan on physical performance in professional soccer players. Br J Sports Med 2007:41:398-400.

45. Kirkendall DT, Leiper JB, Bartagi Z, et al. The influence of Ramadan on physical performance measures in young Muslim footballers. J Sports Sci 2008; 26: $15-27$

46. Fuller CW, Junge A, Dvorak J. An assessment of football referees' decisions in incidents leading to player injuries. Am J Sports Med 2004;32:17S-22S.

47. Hawkins RD, Fuller CW. A prospective epidemiological study of injuries in four English professional football clubs. Br J Sports Med 1999;33:196-203.

48. Maughan RJ, Shirreffs SM, Ozgünen KT, et al. Living, training and playing in the heat: challenges to the football player and strategies for coping with environmental extremes. Scand J Med Sci Sports 2010;20:117-24.

49. Ozgünen KT, Kurdak SS, Maughan RJ, et al. Effect of hot environmental conditions on physical activity patterns and temperature response of football players. Scand J Med Sci Sports 2010;20:140-7.

50. Dvorak J, George J, Junge A, et al. Application of MRI of the wrist for age determination in international U-17 soccer competitions. Br J Sports Med 2007:41:497-500.

51. F-MARC. Fight against Doping in Football: A Comprehensive Introduction and Overview. Zurich: FIFA 2006.

52. Dvorak J, Graf-Baumann T, D'Hooghe M, et al. FIFA's approach to doping in football. Br J Sports Med 2006;40:i3-i12.

53. Aubry M, Cantu R, Dvorak J, et al. Summary and agreement statement of the First International Conference on Concussion in Sport, Vienna 2001. 
Recommendations for the improvement of safety and health of athletes who may suffer concussive injuries. Br J Sports Med 2002;36:6-10.

54. McCrory P, Johnston K, Meeuwisse W, et al. Summary and agreement statement of the $2^{\text {nd }}$ International Conference on Concussion in Sport, Prague 2004. Clin J Sport Med 2005;15:48-55.

55. McCrory P, Meeuwisse W, Johnston K, et al. Consensus statement on Concussion in Sport $3^{\text {rd }}$ International Conference on Concussion in Sport held in Zurich, November 2008. Clin J Sport Med 2009;19:185-200.

56. Fuller $\mathbf{C W}$, Walker J. Quantifying the functional rehabilitation of injured football players. Br J Sports Med 2006;40:151-7; discussion 151-7.

57. Grimm K, Junge A, Dvorak J. Health and Fitness for the Female Football Player: A guide for players and coaches. Zurich: FIFA 2011.

58. Dvorak J, Grimm K, Schmied C, et al. Development and implementation of a standardized precompetition medical assessment of international elite football players-2006 FIFA World Cup Germany. Clin J Sport Med 2009;19:316-21.

59. Kramer E, Dvorak J, Kloeck W. Review of the management of sudden cardiac arrest on the football field. Br J Sports Med 2010;44:540-5.

60. Junge A, Rösch D, Peterson L, et al. Prevention of soccer injuries: a prospective intervention study in youth amateur players. Am J Sports Med 2002;30:652-9.

61. Soligard T, Myklebust G, Steffen K, et al. Comprehensive warm-up programme to prevent injuries in young female footballers: cluster randomised controlled trial. BMJ 2008;337:a2469.
62. Gilchrist J, Mandelbaum BR, Melancon $\mathrm{H}$, et al. A randomized controlled trial to prevent noncontact anterior cruciate ligament injury in female collegiate soccer players. Am J Sports Med 2008;36:1476-83.

63. FIFA. My Game is Fair Play. http://www.fifa.com/aboutfifa/socialresponsibility/ fairplay/ (accessed 1 August 2011).

64. FIFA. FIFA Quality Concept for Football Turf: Handbook of Requirements. Zurich: FIFA 2009.

65. FIFA. Football Stadiums: Technical Recommendations and Requirements. Zurich: FIFA 2011.

66. FIFA. Laws of the Game. Zurich: FIFA 2011.

67. FIFA. FIFA International Matchball Standard: Testing and Certification for Footballs. Zurich: FIFA 2011.

68. Bärtsch P, Saltin B, Dvorak J. Consensus statement on playing football at different altitude. Scand J Med Sci Sports 2008;18:96-9.

69. F-MARC. Nutrition for Football. Zurich: FIFA 2010.

70. Grantham J, Cheung SS, Connes P, et al. Position statement. Current knowledge on playing football in hot environments. Scand J Med Sci Sports 2010;20:161-7.

71. FIFA. Football Medicine Manual. https://extranet.fifa.com/medical/Publications/ Football-Medicine-Manual-2nd-Edition (accessed 23 October 2011).

72. FIFA. F-MARC Football Emergency Manual. Zurich: FIFA 2011.

73. FIFA. Football for Health. 15 Years of F-MARC: Research and Education 19942009. Zurich: FIFA 2011. 